\title{
Pain Simulator Can Improve the Training of Residents and Pain Fellows in Performing Pain Management Procedures
}

\section{TO THE EDITOR:}

We would like to describe a simple simulated practice that we have found to be advantageous in the understanding, and comfort with which multiple pain procedures are performed. The simulated practice utilizes both anatomy and its visualization under fluoroscopy to teach the resident/pain fellow how to perform multiple pain procedures as well as to gain proficiency. The simulated technique not only allows a close simulated experience in every aspect to true patient care but serves to familiarize the resident/pain fellow with the necessary steps employed in each procedure and the necessary radiographic views for spatial orientation.

The resident/pain fellow is given several procedures to review prior to attending a simulator session and then is able to apply the knowledge with practical experience. It serves to cement relationships and procedural knowledge when a visual representation and hands-on-experience intertwine with the textbook readings. The resident/fellow becomes proficient in the procedures listed below. An incredible advantage is gleaned since the resident/fellow is able to not only practice common procedures but also procedures that are less frequently observed.

The simulator allows the resident/fellow to ask questions that may not be as appropriate given a patient setting. The simulator permits the resident/ fellow to practice the procedures as many times as he would like. Furthermore, the more comfortable or acclimated the resident becomes with the process then the more time is spent learning important clinical aspects and troubleshooting rather than the more menial aspects given a true patient clinical setting.

The necessary components that we use in our institution are a spinal injection simulator dummy by Smith Laboratories ${ }^{\mathrm{TM}}$, a portable C-Arm by Siemens Model Siromobil 2000'⿳一 US Imaging Tables Incorporated ${ }^{\mathrm{TM}}$.

The skin of the dummy is made of material that can be used indefinitely without destroying its integ- rity. Also, the contour of the dummy is equivalent to an obese patient making the identification of the anatomical landmarks such as the spinous processes hard to feel and giving the resident/pain fellow a better opportunity to practice on difficult cases.

Examples of procedures that can be simulated:

1. Lumbar epidural steroid injection midline approach.

2. Lumber epidural steroid injection para-median approach.

3. Trans-Foraminal lumbar epidural injection.

4. Lumbar facet joint injection.

5. Sacroiliac joint injection.

6. Medial branch block of the lumbar facet joints.

7. Percutaneous discectomy and all other disc procedures.

8. Discogram.

9. Lumbar sympathetic block.

10. Hypogastric plexus block.

There are some limitations of the simulator and the few that we have found are:

1. The dummy tissue is slightly more rigid than human skin and subcutaneous tissue and for this reason we use an $18 \mathrm{~g}$ spinal needle by Havel's Incorporat$\mathrm{ed}^{\mathrm{TM}}$ in training for all the procedures versus the $22 \mathrm{~g}$ needle that may be used in some procedures in the real patient.

2. Under fluoroscopy the bony anatomy appears slightly darker than in an actual patient but overall the procedure can be visualized easily under fluoroscopy.

3. The dummy spine that we use only ranges from L1 to the sacrum with visualization of the SI joints, so we are only able to simulate procedures in the lumbar and sacral area.

4. We cannot achieve loss of resistance to Epidural steroid injections.

5. We can not inject dye to confirm the needle location or the spread of the dye.

The following pictures will give the readers an idea about the simulator and how it works. 


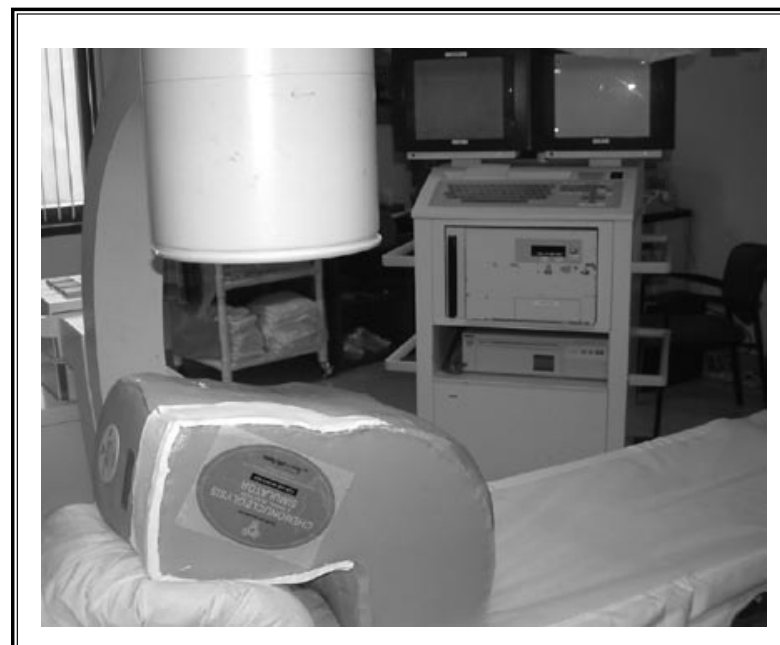

Fig.1. Shows the simulator on the fluoroscopy table using the C-Arm.

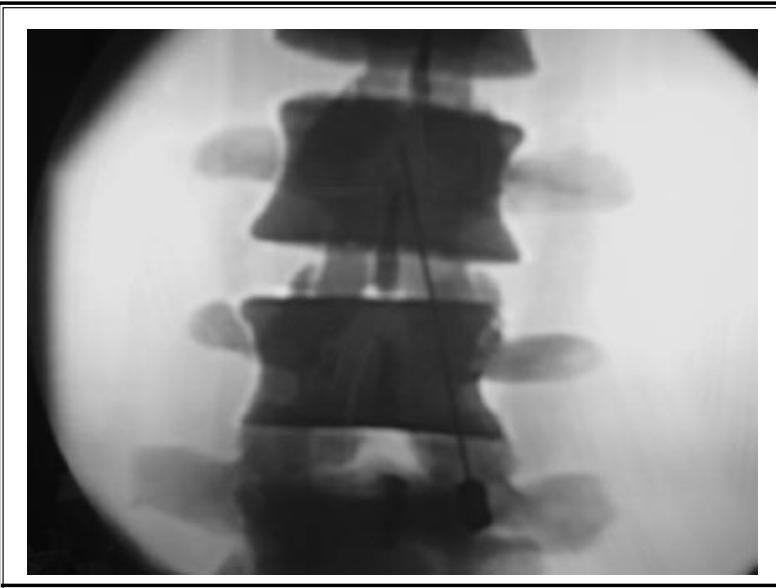

Fig. 3. Shows lumbar epidural para-median approach $A-P$ view.

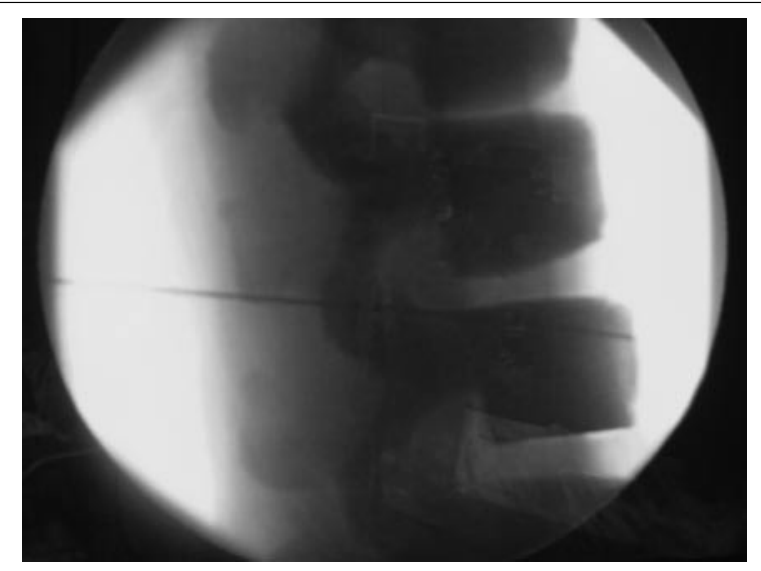

Fig. 5. Shows lumbar sympathetic block lateral view at $L 4$.

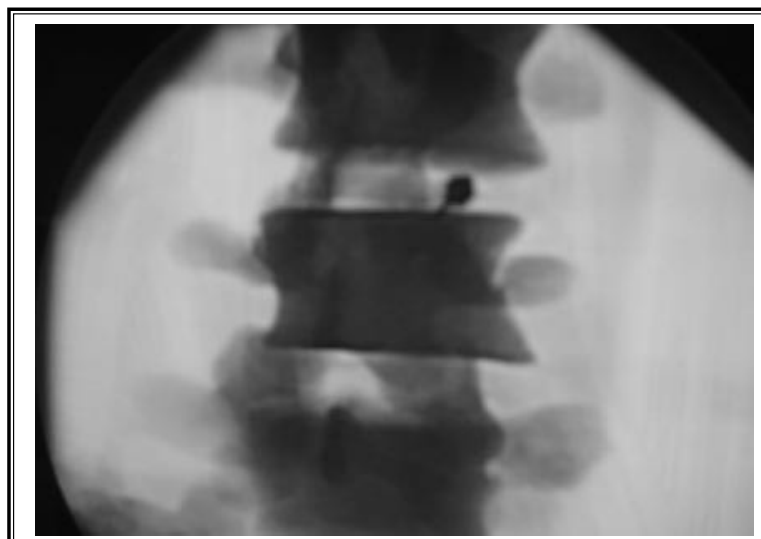

Fig.2 . Shows right facet joint injection at L3-4 level.

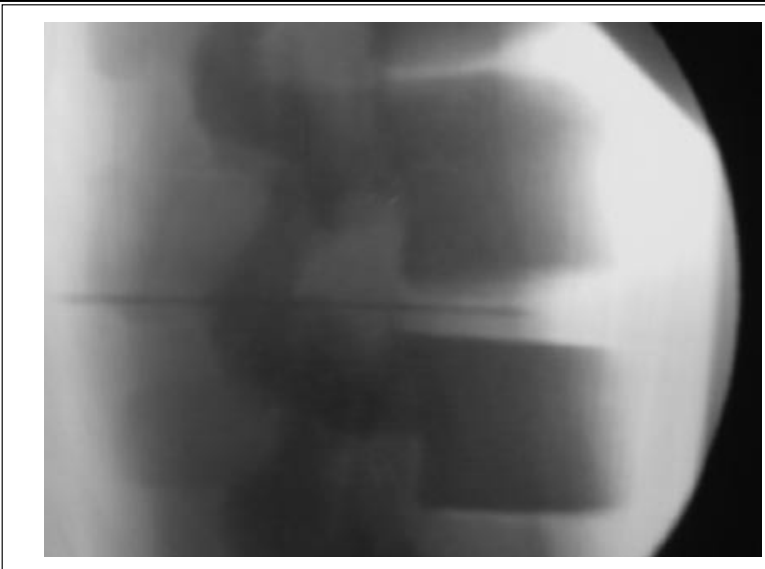

Fig. 4. Shows disc approach lateral view at L3-4.

Joseph Atallah, MD

Director of Pain Management Clinic VAMC

Assistant Professor, Department of Anesthesiology University of Kentucky Chandler Medical Center VA Medical Center, Lexington, Kentucky

1101 Veterans Drive (128-CDD)

Lexington, KY 40502-2236

e-mail: jnatal2@email.uky.edu

Brenda G. Fahy, MD

Professor of Anesthesiology

Department of Anesthesiology

University of Kentucky Chandler Medical Center N-202, 800 Rose Street, Lexington, KY 40536

Tobias Gibson, MD, CA-3 Resident

T. Wade Martin, MD, CA-3 Resident

Department of Anesthesiology

University of Kentucky Chandler Medical Center $\mathrm{N}-202,800$ Rose Street, Lexington, KY 40536 


\section{Topical Lidocaine and Epidural Bupivacaine/ Hydromorphone in the Treatment of Complex Regional Pain Syndrome Type 2}

\section{TO THE EDITOR:}

We report a case of Complex Regional Pain Syndrome (CRPS) type 2 that was successfully treated with a lumbar epidural bupivacaine/hydromorphone infusion and lidocaine $5 \%$ patch to the affected foot. Few reports discuss these options in the treatment of CRPS type 2 and further investigation may be warranted.

A 41-year-old otherwise healthy female noted the insidious onset of left leg radicular pains that led to the diagnosis of a sacral chondrosarcoma that was resected. Her preoperative course was complicated by a venous thrombosis in the left leg that was treated with anticoagulation and an IVC filter. During the resection, the left $\mathrm{S} 1$ nerve root was sacrificed. The patient noted a progressive burning dysesthesia in the left foot postoperatively that required readmission 6 weeks later. Pain rating was 10 out of 10 on the visual analogue scale at readmission. General examination and the surgical site were unremarkable. Even though sensory and motor findings were consistent with an S1 root lesion, the patient experienced pain in the entire foot well beyond S1 dermatome. The foot was erythematous, warm, slightly edematous, and demonstrated marked mechanical allodynia throughout. Pulses were strong and symmetric. There was no significant edema, trophic changes, or tenderness over the calf. Pregabilin, tizanidine, benzodiazepines, mirtazapine, and opiates weren't helpful, so a lumbar epidural catheter was placed and an infusion of $0.125 \%$ bupivacaine and $10 \mathrm{mcg} / \mathrm{mL}$ of hydromorphone at $6 \mathrm{~mL} / \mathrm{hr}$ was begun. Pain was improved the next day to 5 out of 10 . A lidocaine $5 \%$ topical patch was then applied and by the following day her pain was just one out of 10. Three days later she had minimal allodynia and decreased erythema and was discharged from the hospital. Follow up in the surgical center has found her to be doing very well with minimal pain. She still uses the lidocaine patch in addition to tizanindine, pregabalin, and oxycodone/acetaminophen as needed. She is off sustained release oxycodone.

Numerous medications have been tried to treat CRPS with varying success (1). One open label study of lidocaine $5 \%$ topical patches demonstrated an effect on patients with CRPS (2), but other reports of topical lidocaine's utility in this condition are scarce. Likewise, little information regarding epidural analgesia with local anesthetics or opiates as a treatment of CRPS is to be found, though there does exist reference to epidural injections as a sympatholytic option (3) and to epidural infusion as a preventative measure perioperatively (4). Our patient had such a significant response to these 2 modalities that it seemed worth reporting to garner attention to such interventions.

Regarding the diagnostic impression that this was in fact CRPS, a few points should be made. Her case is confounded by venous thrombosis in the ipsilateral leg, infectious/inflammatory mimics weren't ruled out, and neither nuclear isotope imaging nor MRI was performed on the affected foot. Furthermore, she was on other medications that may have contributed to pain control, and one could argue that the case represents a traumatic $\mathrm{S1}$ radiculopathy. We felt that the thrombosis wasn't the source of her pain because it had been present preoperatively and was being treated prior to the development of her burning dysesthetic pain. Infection and non-infectious inflammatory disorders seem unlikely as she improved in the absence of antibiotic or anti-inflammatory medications. Though we requested a bone scan and MRI with gadolinium, these weren't performed and treatment was more urgent than diagnostic testing that are not necessarily sensitive or specific for CRPS (5). Regarding her other medications, the strongest temporal correlation with her improvement was with the epidural medications and topical lidocaine. Finally, her pain included but also extended beyond the $\mathrm{S} 1$ dermatome, involving the entire foot.

From a pathophysiologic standpoint, this case may provide insight into the mechanisms by which CRPS type 2 develops. A variety of pain related phenomena, both central and peripheral, have been associated with the development of neuropathic pain. A continuum starting with "irritability" of the nociceptive system at one end and almost complete deafferentation on the other end has been demonstrated in the same neu- 
ropathic pain disorder, postherpetic neuralgia $(6,7)$. Several features of peripheral sensitization occur early during PHN, including a reduction in the threshold of pain caused by heat at the site of erythematous skin, a phenomenon that disappears later in the natural history of the disease when abnormal responses in the central nervous system dominate the clinical picture (8). It is probably not a coincidence that the lidocaine $5 \%$ patch, a topical preparation with minimal systemic absorption, is more effective in postherpetic neuralgia than in many other neuropathic pain conditions where the peripheral sensitization doesn't play such a significant role in the pain manifestation (9).

Central sensitization is the most likely physiological phenomenon that underlines the clinical spectrum of pain features seen in CRPS (10). Central sensitization amplifies and facilitates the synaptic transfer from the nociceptor central terminal to dorsal horn neurons. During the late phase of central sensitization, it is sustained beyond the initiating stimulus by transcriptional changes in the molecular machinery of the cell (11). That may explain a relative lack of efficacy of medications targeting peripheral mechanisms of neuropathic pain seen in many patients with established CRPS. However, in CRPS type 2, with its distinct peripheral nerve (or dorsal root, as in the presented case) injury, peripheral sensitization might play a much more important role in the development of this usually recalcitrant pain syndrome, compared to CRPS type 1 when the initial event is often minor or, sometimes, even can't be recalled by the patient. Therefore, the pathogenesis of CRPS type 2 may not be dissimilar to that of postherpetic neuralgia that starts with the peripheral sensitization process, and then proceeds through the acute phase of central sensitization to the full-fledged late phase of central sensitization associated with intractable spreading pain poorly responsive to topical preparations. It has been demonstrated that the early stage of central sensitization, which our case of nascent CRPS type 2 might represent, is actively dependent on nociceptive input into the spinal cord $(12,13)$. Thus, such agents as lidocaine $5 \%$ patch or/ and prolonged regional block with local anesthetic in the epidural space could interrupt the sensory barrage from the periphery which maintains the acute central sensitization and, therefore, might be proven of great value if used in the very early stages of developing CRPS type 2.

The above case suggests that application of local anesthetics to sites along the peripheral nervous system and into the epidural space early in the course of CRPS type 2 may be able to shut down the process by which the disorder establishes itself. That these 2 treatments seemed so effective warrants more investigation and may suggest a strong peripheral component to the initial stages of CRPS type 2 .

Yakov Vorobeychik, MD

Assistant Professor of Anesthesiology and Neurology Milton S. Hershey Medical Center

500 University Drive, HU32

Hershey, PA 17033

e-mail: yvorobeychik@psu.edu

David M. Giampetro, MD

Assistant Professor of Anesthesiology and Neurology Milton S. Hershey Medical Center

500 University Drive, HU32

Hershey, PA 17033

\section{References}

1. Kingery WS. A critical review of controlled clinical trials for peripheral neu- 6 . ropathic pain and complex regional pain syndrome. Pain 1997; 73:123-139.

2. Devers A, Galer BS. Topical lidocaine patch relieves a variety of neuropath- 7 ic pain conditions: an open-label study. Clin J Pain 2000; 16:205-208.

3. Gordon N. Reflex sympathetic dystrophy. Brain \& Development 1996; 18:257- 8 262.

4. Reuben, SS. Preventing the development of complex regional pain syndrome after surgery. Anesthesiology 9 2004; 101:1215-1224

5. Bruehl S, Harden RN, Galer BS, Saltz S, Backonja M, Stanton-Hicks M. Complex regional pain syndrome: are there distinct subtypes and sequential stages of the syndrome? Pain 2002; 95:119-124. Fields HL, Rowbotham M, Baron R. Postherpetic neuralgia: irritable nociceptors and deafferentation. Neurobiol Dis 1998; 5:209-227.

7. Rowbotham M. Mechanisms of neuropathic pain and their implications for the design of clinical trials. Neurology 2005; 65(Suppl 4):S66-S73.

8. Rowbotham M, Fields HL. The relationship of pain, allodynia and thermal sensation in post-herpetic neuralgia. Brain 1996; 119:347-354.

Dworkin R, Backonja M, Rowbotham M, Allen RR, Argoff CR, Bennet GJ, Bushnell MC, Farrar JT, Galer BS, Haythornthwaite JA, Hewitt DJ, Loeser JD, Max MB, Saltarelli M, Schmader KE, Stein C, Thompson D, Turk DC, Wallace MS,
Watkins LR, Weinstein SM. Advances in neuropathic pain. Arch Neurol 2003; 60:1524-1534.

10. Schwartzman R, Vorobeychik Y. Complex regional pain syndrome I/II. In: Evans R (ed): Neurology and Trauma. New York. Oxford University Press 2006; pp. 465-476.

11. Ji RR, Kohno T, Moore KA, Woolf CJ. Central sensitization and LTP: do pain and memory share similar mechanisms? TINS 2003; 26:696-705.

12. Woolf CJ, Salter MW. Neuronal plasticity: increasing the gain in pain. Science 2000; 228:1765-1769.

13. Woolf $\mathrm{CJ}$. Pain: moving from symptom control toward mechanism-specific pharmacologic management. Ann Intern Med 2004; 140:441-451. 


\section{Request for Additional Pertinent Information Regarding 4 Extremity Stimulation Coverage from C2 Spinal Cord Stimulation Lead Placement}

\section{TO THE EDITOR:}

The recent case series, "Neuromodulation of the Cervical Spinal Cord in the Treatment of Chronic Intractable Neck and Upper Extremity Pain: A Case Series and Review of the Literature," by Vallejo, Kramer, and Benyamin, (Pain Physician 2007; 10:305-311) furnishes us with valuable, insightful information regarding the ability to achieve moderate to excellent paresthesia coverage of all 4 extremities in certain patients.

In our practice, this has been a substantially helpful way in dealing with various diagnoses. This tool is predominately helpful in Complex Regional Pain Syndromes (CRPS), but has been an advantage in treating pain from multiple sclerosis, peripheral vascular disease, diabetes, and some comorbid conditions. We have found that 4-extremity coverage is achieved when the lead is placed with the rostral electrode tips in the $\mathrm{C} 2$ region with electrode strings over the physiologic midline (1).

Additionally, in our experience, this phenomenon appears to have some dependence upon the type of SCS architecture employed: we were unable to achieve 4-limb paresthesias in systems which utilize a singlecurrent source stimulation (voltage controlled) with a frequency limit of $120 \mathrm{~Hz}$. Utilizing a single-current source for stimulation which permitted frequencies up to $1500 \mathrm{~Hz}$, we saw a $15 \%$ incidence of stimulation in all 4 extremities. We have most commonly seen 4-extremity coverage ( $84 \%$ of patients with lead tip placement at $\mathrm{C2}$ ) using a system architecture which allows multiple independent constant current (MICC); this design allows the physician or SCS programmer the ability to control amplitude, pulse width, and frequency independently at each electrode simultaneously, not utilizing a program cycling mode (2).

We appreciate the technical problems with lead placements at these high cervical levels after anterior or anterior-posterior cervical fusion. Our solution has been to perform a small hemi-laminotomy at C3-4 to ease lead entry and positioning. Even after instrumentation of the cervical spine with anterior and posterior

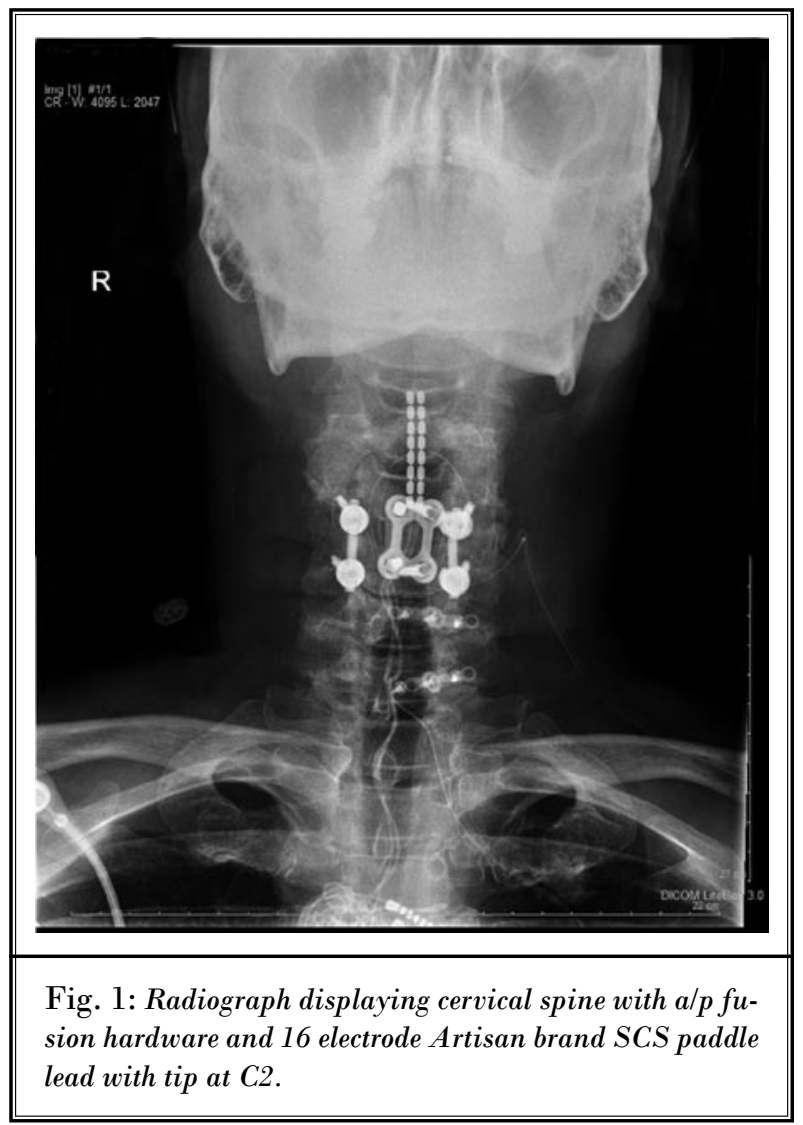

hardware, placement of a paddle lead is technically simple (Fig.1).

Our concern in Vallejo et al's case series is that 2 valuable pieces of clinical information were not included. The specific equipment utilized for each case would offer the reader important information as to whether the differences in technology were able to provide a greater chance of providing paresthesia and pain relief in this cohort. Secondly, an important, possibly critical piece of information is the mention of pulse width, frequency of stimulation (rate), and power settings used for each case. It is our opinion that since spinal cord stimulation is a functional surgical procedure, 
the settings utilized along with electrode position and polarity in relation to the neural targets is vital to determining the reason for success or failure (3).

As a clinical neurophysiologist responsible for intra- and post-operative programming, I would find it helpful to have such information. Publications which detail the specific technologies and programmed settings employed, and link these values to outcomes are an invaluable guide to the practicing clinicians. These data can even guide us in the pre-operative choice of equipment for implantation.

We thank the authors for their excellent case series and hope that this will inspire more clinicians to publish their unique experiences in our rapidly advancing practice of electrical neuromodulation.

\author{
James E. Hagen, MS \\ Director, Clinical Services and Research \\ Daniel S. Bennett, MD \\ Medical Director \\ Integrative Treatment Centers-Denver \\ 10835 N. Dover St, Suite 800 \\ Westminster, CO 80021 \\ jhagen@denverpain.com
}

\section{References}

1. Hagen JE, Bennett DS. Successful treat ment of 4-extremity complex regional pain syndrome type 1 with dual octapolar percutaneous leads and closely spaced electrodes. Poster Presentation, 7th Congress of the International Neuromodulation Society; Rome, Italy June 10-13, 2005.
2. Oakley J, Varga C, Krames E, Bradley K. 3 Real-time paresthesia steering using continuous electrical field adjustment. Part 1: intraoperative performance. Neuromodulation 2004; 7:157-167.
Gordon AT, Zou SP, Kim Y, Gharibo C. Challenges to setting spinal cord stimulator parameters during intraoperative testing: factors affecting coverage of low back and leg pain. Neuromodulation 2007; 10:133-141.

\section{Author Response to: Request for Additional Pertinent Information Regarding 4 Extremity Stimulation Coverage from C2 Spinal Cord Stimulation Lead Placement}

We would like to thank Hagen and Bennett for their enthusiastic comments about our paper titled, "Neuromodulation of the Cervical Spinal Cord in the Treatment of Chronic Intractable Neck and Upper Extremity Pain: A Case Series and Review of the Literature" (1). We agree with the authors that the placement of leads in the cervical region can be very beneficial to patients that suffer from painful conditions in widely separated regions of the body. Indeed, our case series highlights this point even to the extent of patients indicating coverage of occipital regions as well as all 4 extremities. We appreciate the reporting of similar clinical experiences from this group, as well as others (2). Hagen and Bennett state that approximately $84 \%$ of their patients report 4-extremity coverage with lead tip placement at C2 (3). In our case series, all 4 out of 4 patients (100\%) that implanted indicated the ability to obtain coverage in all 4 extremities. With a larger patient population to sample from this percentage may drop closer to the $84 \%$ reported by Hagen and Bennett (3). Interestingly, 2 out of the 4 patients also reported axial coverage. We feel that this is an important distinction and note that these 2 patients had devices implanted from 2 different companies, both of which were constant current type units. We reported that stimulators from 3 different manufacturers were utilized in the current case series. Given the low number of patients included in our case series, it is impossible to attribute "whether differences in technology were able to provide a greater chance of providing paresthesia and pain relief in this cohort" (3). However, we agree that stimulation parameters can be a valuable piece of information, so we have included the stimulation settings for all of those included in the case series that underwent device implantation (see Table 1). We absolutely agree that stimulation parameters as well as differences in lead and pulse generator technology may well play a role in the clinical efficacy of spinal neuromodulation. In particular, we were interested to read that high stimulation frequencies $(1500 \mathrm{~Hz})$ may increase the chance of generating paresthesias in 4 limbs. In our experience, longer pulse widths also seem to be associated with the ability to generate paresthesias map- 
Table 1. Stimulation parameters for multiple programs utilized in patients implanted with spinal cord stimulation systems.

\begin{tabular}{|c|c|c|c|}
\hline B & $\begin{array}{l}\text { Constant } \\
\text { Current }\end{array}$ & $\begin{array}{l}\text { P 1: } 50 \mathrm{~Hz} \\
\text { P 2: } 50 \mathrm{~Hz}\end{array}$ & $\begin{array}{l}\text { P 1: } 620 \mu \mathrm{s} \\
\text { P 2: } 470 \mu \mathrm{s}\end{array}$ \\
\hline$C$ & $\begin{array}{l}\text { Constant } \\
\text { Current }\end{array}$ & $\begin{array}{l}\text { P 1: } 60 \mathrm{~Hz} \\
\text { P 2: } 80 \mathrm{~Hz} \\
\text { P 3: } 38 \mathrm{~Hz} \\
\text { P 4: } 38 \mathrm{~Hz}\end{array}$ & $\begin{array}{l}\text { P 1: } 187 \mu \mathrm{s} \\
\text { P 2: } 150 \mu \mathrm{s} \\
\text { P 3: } 200 \mu \mathrm{s} \\
\text { P 4: } 200 \mu \mathrm{s}\end{array}$ \\
\hline D & $\begin{array}{l}\text { Constant } \\
\text { Current }\end{array}$ & $\begin{array}{l}\text { P 1: } 20 \mathrm{~Hz} \\
\text { P 2: } 60 \mathrm{~Hz} \\
\text { P 3: } 80 \mathrm{~Hz}\end{array}$ & $\begin{array}{l}\text { P 1: } 450 \mu \mathrm{s} \\
\text { P 2: } 425 \mu \mathrm{s} \\
\text { P 3: } 425 \mu \mathrm{s}\end{array}$ \\
\hline$E$ & $\begin{array}{l}\text { Constant } \\
\text { Current }\end{array}$ & $\begin{array}{l}\text { P 1: } 40 \mathrm{~Hz} \\
\text { P 2: } 40 \mathrm{~Hz}\end{array}$ & $\begin{array}{l}\text { P 1: } 580 \mu \mathrm{s} \\
\text { P 2: } 500 \mu \mathrm{s}\end{array}$ \\
\hline
\end{tabular}

ping from the occipital region down to the toes with high cervical lead placement. However, until quantitative sensory mapping studies as well as randomized, direct head-to-head trials are completed between devices, these types of clinical data will continue to remain anecdotal.
Ricardo Vallejo, MD, PhD

Jeffrey Kramer, PhD

Ramsin Benyamin, MD

Millennium Pain Center

1015 S. Mercer Ave.

Bloomington, Illinois, 61701

vallejo@millenniumpaincenter.com

\section{RefEREnCES}

1. Vallejo, R, Kramer, JM, Benyamin, R neuromodulation of the cervical spinal cord in the treatment of chronic intractable neck and upper extremity pain: a case series and review of the literature. Pain Physician 2007; 10:305-311.
2. Rauck, R., Wages, J, North, J. Four ex- 3 . tremity paresthesias with cervical spinal cord stimulation. Poster Presentation, 26th Annual Meeting of the American Pain Society; Washington, DC, May 2-5, 2007.
Hagen, JE, Bennett, DS Request for additional pertinent information regarding 4 extremity stimulation coverage from C2 spinal cord stimulation lead placement. Pain Physician 2007; 10:

\section{In ErRata:}

The address listed for Dr. Michael Whitworth in the letters to the editor section of the March Pain Physician journal was incorrect.

The correct address is

Michael L. Whitworth, MD

Advanced Pain Management Surgery

4010 Goeller Blvd Suite C

Columbus, IN 47201 
